\title{
Correction: Lipton et al., Interactions within the Hand Representation in Primary Somatosensory Cortex of Primates
}

In the article "Interactions within the Hand Representation in Primary Somatosensory Cortex of Primates" by Michael L. Lipton, Mark C. Liszewski, M. Noelle O’Connell, Aimee Mills, John F. Smiley, Craig A. Branch, Joseph R. Isler, and Charles E. Schroeder, which appeared on pages 15895-15903 of the November 24, 2010 issue, the authors regret that the National Institute of Deafness and Other Communicative Disorders (NIDCD) Grant 5-R01-DC011490 to C.E.S. and T.A.H. was omitted from the acknowledgments. The correct acknowledgment is printed below.

This work was supported in part by National Institutes of Health Grants K08-MH67082 (M.L.L.) and R01-DC011490 (C.E.S. and T.A.H.), and National Science Foundation Grant NSF-0519410 (C.E.S.).

DOI: 10.1523/JNEUROSCI.3920-15.2015 